Teruhiko Sato $\cdot$ Kuniaki Seyama $\cdot$ Hiroaki Fujii

Hiroshi Maruyama $\cdot$ Yasuhiro Setoguchi

Shin-ichiro Iwakami • Yoshinosuke Fukuchi

Okio Hino

\title{
Mutation analysis of the TSC1 and TSC2 genes in Japanese patients with pulmonary lymphangioleiomyomatosis
}

Received: August 30, 2001 / Accepted: November 2, 2001

\begin{abstract}
Pulmonary lymphangioleiomyomatosis (LAM) is a destructive lung disease characterized by a diffuse hamartomatous proliferation of smooth muscle cells (LAM cells) in the lungs. Pulmonary LAM can occur as an isolated form (sporadic LAM) or in association with tuberous sclerosis complex (TSC) (TSC-LAM), a genetic disorder with autosomal dominant inheritance with various expressivity resulting from mutations of either the TSC1 or TSC2 gene. We examined mutations of both TSC genes in 6 Japanese patients with TSC-LAM and 22 patients with sporadic LAM and identified six unique and novel mutations. TSC2 germline mutations were detected in $2(33.3 \%)$ of 6 patients with TSC-LAM and TSC1 germline mutation in $1(4.5 \%)$ of 22 sporadic LAM patients. In accordance with the tumorsuppressor model, loss of heterozygosity (LOH) was detected in LAM cells from 3 of 4 patients with TSC-LAM and from 4 of 8 patients with sporadic LAM. Furthermore, an identical $\mathrm{LOH}$ or two identical somatic mutations were demonstrated in LAM cells microdissected from several tissues, suggesting LAM cells can spread from one lesion to another. Our results from Japanese patients with LAM con-
\end{abstract}

T. Sato $\cdot$ K. Seyama $(\bowtie) \cdot$ Y. Setoguchi $\cdot$ S. Iwakami $\cdot$ Y. Fukuchi Department of Respiratory Medicine Juntendo University, School of Medicine, 2-1-1 Hongo, Bunkyo-Ku, Tokyo 113-8421, Japan

Tel. +81-3-5802-1063; Fax +81-3-5802-1617

e-mail: kseyama@med.juntendo.ac.jp

H. Fujii

Department of Pathology Juntendo University, School of Medicine,

Tokyo, Japan

K. Seyama $\cdot$ Y. Fukuchi

Atopy (Allergy) Research Center, Juntendo University, School of Medicine, Tokyo, Japan

T. Sato $\cdot$ K. Seyama $\cdot$ O. Hino

Department of Experimental Pathology, Cancer Institute, Tokyo, Japan

H. Maruyama

Department of Pathology, Hoshigaoka Koseinenkin Hospital,

Hirakata, Japan firmed the current concept of pathogenesis of LAM: TSCLAM has a germline mutation but sporadic LAM does not; sporadic LAM is a TSC2 disease with two somatic mutations; and a variety of TSC mutations causes LAM. However, our study indicates that a fraction of sporadic LAM can be a TSCl disease; therefore, both TSC genes should be examined, even for patients with sporadic LAM.

Key words Pulmonary lymphangioleiomyomatosis (LAM) - Tuberous sclerosis complex (TSC) - Forme fruste - TSC1 . TSC2 - Germline mutation - Somatic mutation - Loss of heterozygosity $(\mathrm{LOH})$

\section{Introduction}

Pulmonary lymphangioleiomyomatosis (LAM) is a rare disease that almost exclusively affects women of reproductive age and is characterized by hamartomatous proliferation of abnormal smooth muscle cells (LAM cells) along the alveolar wall, vessels and lymphatics in the lungs, and occasionally mediastinal or retroperitoneal lymph nodes (Corrin et al. 1975; Silverstein et al. 1974). Clinical manifestations of pulmonary LAM include recurrent spontaneous pneumothorax, progressive dyspnea on exertion, chylothorax, and hemoptysis (Corrin et al. 1975; Silverstein et al. 1974). The most common features of pulmonary function in patients with pulmonary LAM is the impairment of diffusing capacity and airflow obstruction (Chu et al. 1999; Corrin et al. 1975; Johnson and Tattersfield 1999; Silverstein et al. 1974; Urban et al. 1999). LAM has a diverse clinical course and some patients retain a good pulmonary function for a long period without antihormone therapy, although others show progressive deterioration leading to respiratory failure and cor pulmonale (Seyama et al. 2001). Although LAM has been commonly recognized as a sporadic, noninherited pulmonary disease (sporadic LAM), it has also been known to develop in about $1 \%-4 \%$ of patients with tuberous sclerosis complex (TSC) (TSC-LAM) (Castro et al. 1995; Gomez 1999). TSC is a hereditary disor- 
der with an autosomal dominant trait, characterized by seizures; mental retardation; and hamartomas of the brain, retina, skin, heart, lungs, and kidneys (Gomez 1999; Short et al. 1995). TSC is a tumor-suppressor gene syndrome in which Knudson's two-hit theory (Knudson 1971) is applied for the development of TSC-associated hamartoma (Henske et al. 1996; Sepp et al. 1996) and patients with TSC have a germline mutation of either the TSC1 or the TSC2 gene (Jones et al. 1997, 1999; Wilson et al. 1996; Yamashita et al. 2000). The TSC1 gene codes for a $130-\mathrm{kDa}$ protein named hamartin, which is located on chromosome 9q34 (Van Slegtenhorst et al. 1997), and the TSC2 gene codes for a 200-kDa protein named tuberin (Consortium 1993), located on chromosome 16p13.3.

Recent studies have indicated that angiomyolipomas and lymph nodes from patients with sporadic LAM have a TSC2 loss of heterozygosity ( $\mathrm{LOH})$ but not a TSC1 LOH (Smolarek et al. 1998). Patients with sporadic LAM were demonstrated not to carry the TSC2 germline mutation (Astrinidis et al. 2000); inactivating mutations of the retained TSC2 allele have been demonstrated in the affected tissues but not in unaffected tissues from patients with sporadic LAM (Carsillo et al. 2000). These findings clearly indicate that sporadic LAM is different from TSC-LAM with either the TSC1 or TSC2 germline and is caused by two somatic mutations of TSC2 in individuals without TSC. In this study, we analyzed mutations of the TSC genes in 28 Japanese patients with LAM to confirm the recent advances in pathogenesis of LAM and we report six novel mutations.

\section{Materials and methods}

\section{Study group}

This study was approved by the Institutional Ethical Board of Juntendo University Hospital and the informed consent from patients was obtained prior to their enrollment in this study. A total of 28 female patients with a diagnosis of LAM, confirmed by pathological examination of the lung specimen, were enrolled. Six had a clinical diagnosis of TSC according to the recently revised diagnostic criteria (Gomez 1999) and were defined as having TSC-LAM, and the remaining 22 patients had sporadic LAM with no dermatological or neurological signs and symptoms characteristic of TSC.

Genomic DNA was isolated from peripheral blood leukocytes and/or from an Epstein-Barr virus (EBV)transformed lymphoblastoid cell line (EBV-LCL) that was established from peripheral blood mononuclear cells. Total RNA was isolated from EBV-LCL using TRIzol (Life Technologies, Rockville, MD, USA), and guanidine isothiocyanate extraction with ultracentrifugation was used for isolating total RNA from frozen tissues such as the lung and lymph nodes. cDNA primed with oligo(deoxythymidine)15-17 was synthesized from $5 \mu \mathrm{g}$ of total RNA in $20 \mu \mathrm{l}$ of reaction volume using a cDNA synthesis kit (Life Technologies).
Screening of mutations of the TSC1 and TSC2 genes

A dideoxy fingerprinting method (ddF) (Sarkar et al. 1992) was used for screening mutations of the TSC genes when RNA was available from EBV-LCL and tissue specimen. On the other hand, a single-strand conformational polymorphism (SSCP) method was used as described previously (Yamashita et al. 2000) when only genomic DNA was available for analysis. Reverse transcriptase-polymerase chain reaction (RT-PCR) (using cDNA as a template) of the TSC genes was performed using several pairs of primers designed to cover the entire coding region of each gene. The entire coding region of the TSC1 gene was divided into two overlapping fragments and amplified separately by RTPCR; a pair of P1 and P10 primers generated a DNA fragment (2030bp) derived from the 5' side of the TSC1 gene and a pair of P9 and P17 generated DNA fragments (1911 bp) derived from the 3' side of the TSC1 gene (Table 1). Primers used for RT-PCR of the TSC2 gene were adopted from the study reported by Wilson et al. (1996); three overlapping DNA fragments (1963bp, $2357 \mathrm{bp}$, and $1411 \mathrm{bp}$ ) were generated. RT-PCR was performed using Expand Long Template PCR system (Roche Diagnostics, Tokyo, Japan) according to the manufacturer's instruction. The reaction mixture contained $1.0 \mu$ l of cDNA solution, $2.25 \mathrm{mM} \mathrm{MgCl} 2,500 \mu \mathrm{M}$ deoxyribonucleoside triphosphate (dNTP), 300 nM primers, and 2.5 units of DNA polymerase mixture (Taq and Pwo polymerases) in $50 \mu \mathrm{l}$ of reaction volume. The thermal cycler (Model 9600, PE Biosystems, Chiba, Japan) condition was 10 cycles of denaturation $\left(93^{\circ} \mathrm{C}, 15 \mathrm{~s}\right)$, annealing $\left(60^{\circ} \mathrm{C}, 30 \mathrm{~s}\right)$, and extension $\left(68^{\circ} \mathrm{C}\right.$, $2 \mathrm{~min})$, followed by 20 cycles of denaturation $\left(93^{\circ} \mathrm{C}, 15 \mathrm{~s}\right)$, annealing $\left(60^{\circ} \mathrm{C}, 30 \mathrm{~s}\right)$, and extension $\left(68^{\circ} \mathrm{C}, 2 \mathrm{~min}\right.$ and $\left.20 \mathrm{~s}\right)$ with a 20 -s increment of extension time for each cycle. RTPCR products were loaded onto agarose gel electrophoresis and amplified DNA fragments of both TSC1 and TSC2 genes were cut from the gel and purified using Qiaex II DNA extraction kit (Qiagen, Tokyo, Japan). Purified DNA fragments were used to screen mutations of the TSC1 or TSC2 gene, respectively, by ddF; primers used for screening the TSC1 gene by ddF are shown in Table 1 those for the TSC2 gene were adopted from the study reported by Wilson et al. (1996). The ddC (2',3'-dideoxycytidine $5^{\prime}$-triphosphate) sequence reaction was performed with the ThermoSequenase cycle sequencing kit (Amersham Pharmacia Biotech, Tokyo, Japan) according to the manufacturer's instruction. When an aberrant band was detected by ddF, nucleotide alteration was confirmed by sequencing (described following).

\section{Sequencing of the TSC genes}

To determine the sequence alteration, we amplified a part of the TSC genes by PCR using genomic DNA (Yamashita et al. 2000) or cDNA (described earlier); sources of genomic DNA were either peripheral blood leukocytes, EBVLCL, or paraffin-embedded tissue specimens (described following). Amplified DNA fragments were purified from 
Table 1. Oligonucleotide primer used in the analysis of the TSC1 gene

\begin{tabular}{|c|c|c|c|}
\hline Primer name & Sequence & Direction $^{\mathrm{a}}$ & Location $^{\mathrm{b}}$ \\
\hline P1 & 5'-ACTGAAGTACCAGTTGTCGCTAG-3' & $\mathrm{F}$ & nt $114-136$ \\
\hline P2 & 5'-ATCCTGACCACСТTGCAAGAGC-3' & $\mathrm{F}$ & nt $398-420$ \\
\hline P3 & 5'-TGGCCGTCTGTCATCATGGTGC-3' & $\mathrm{F}$ & nt $695-716$ \\
\hline P4 & 5'-GATGTTGTGATCGAGTGTGCCA-3' & $\mathrm{F}$ & nt $981-1002$ \\
\hline P5 & 5'-TTACTCCACGTCTCGGCTGATG-3' & $\mathrm{F}$ & nt $1154-1175$ \\
\hline P6 & 5'-GAAGATGGTGTTGTCTGTGTAG-3' & $\mathrm{R}$ & nt $1515-1536$ \\
\hline P7 & 5'-АCTCTAAGTGATCTTCCAGGGT-3' & $\mathrm{F}$ & nt $1584-1605$ \\
\hline P8 & 5'-GAAAGTTCTCTAGATATTGCAG-3' & $\mathrm{R}$ & nt $1660-1681$ \\
\hline P9 & 5'-GCAAGCCTTTACTCCCATAG-3' & $\mathrm{F}$ & nt $1868-1887$ \\
\hline $\mathrm{P} 10$ & 5'-GGCACACCATCTTCCTCTG-3' & $\mathrm{R}$ & nt $2125-2143$ \\
\hline P11 & 5'-GACAGACTGATACAGCAGGGAG-3' & $\mathrm{F}$ & nt $2169-2190$ \\
\hline $\mathrm{P} 12$ & 5'-CTAGATACAATCAGCTCCAGGA-3' & $\mathrm{F}$ & nt $2497-2518$ \\
\hline $\mathrm{P} 13$ & 5'-GTCAACGAGCTCTATTTGGAAC-3' & $\mathrm{F}$ & nt $2793-2814$ \\
\hline P14 & 5'-CAGGTGTTTGAATTGGAGATCT-3' & $\mathrm{F}$ & nt $3087-3108$ \\
\hline $\mathrm{P} 15$ & 5'-GGCAGTAGTGGAAGCAGAGG-3' & $\mathrm{F}$ & nt $3303-3322$ \\
\hline P16 & 5'-CATGACCAGTAGCCTTTCTGA-3' & $\mathrm{F}$ & nt $3545-3565$ \\
\hline P17 & 5'-GCATTCACACCTCCTGTTCT-3' & $\mathrm{R}$ & nt $3759-3778$ \\
\hline
\end{tabular}

${ }^{\mathrm{a}} \mathrm{F}$, forward primer; $\mathrm{R}$, reverse primer

${ }^{\mathrm{b}}$ The nucleotide number (nt) was adopted from the sequence data of the TSC1 gene (GenBank, accession number AF013168); the A nucleotide of the first methionine (ATG) of the TSC1 gene was assigned as nt 222

agarose gel as described earlier and followed by direct sequencing using $\left[{ }^{32} \mathrm{P}\right]$-labeled primers and ThermoSequenase cycle sequencing kit (Amersham Pharmacia Biotech). When cloning of the PCR product was required, a pTA cloning kit (Invitrogen, Carlsbad, CA, USA) was used according to the manufacturer's instruction.

Microdissection of smooth muscle cells from paraffin-embedded tissues

Formalin-fixed and paraffin-embedded tissue specimens were used to dissect proliferating smooth muscle cells (LAM cells) and control cells such as bronchial epithelial cells and lymphocytes, followed by DNA extraction and genetic analysis (Fujii et al. 1996). Multiple sections $8 \mu \mathrm{m}$ in thickness were deparaffinized, stained with hematoxylin and eosin, visualized with an inverted microscope, and dissected using a 26-gauge needle. Microdissected smooth muscle cells were digested overnight in $15-30 \mu l$ of lysis buffer containing $50 \mathrm{mM}$ Tris- $\mathrm{HCl}(\mathrm{pH} 8.0), 1 \mathrm{mM}$ ethylenediaminetetraacetate (EDTA), $0.5 \%$ NP-40, and $200 \mu \mathrm{g} / \mathrm{ml}$ proteinase K. The lysate was used directly in PCR for LOH analysis or preparing template DNA fragments for direct sequencing.

$\mathrm{LOH}$ analysis of microsatellite markers at chromosomes 9q34 and 16p13.3

Microsatellite markers were selected according to Smolarek et al. (1998): D9S149, D9S1198, and D9S1199 for chromosome 9q34, and D16S283, D16S291, D16S525, and Kg8 for chromosome $16 \mathrm{p} 13.3$. PCR was performed in $10 \mu \mathrm{l}$ of reaction buffer $\left(10 \mathrm{mM}\right.$ Tris- $\mathrm{HCl}$ at $\mathrm{pH} 8.3$ at $25^{\circ} \mathrm{C}, 50 \mathrm{mM} \mathrm{KCl}$, $0.1 \%$ Triton $\mathrm{X}-100)$ containing $1.0 \mu \mathrm{l}$ of DNA solution, $1-2 \mathrm{mM} \mathrm{MgCl} 2,200 \mu \mathrm{M}$ dNTP, $250 \mathrm{nM}$ primers, $0.25 \mu \mathrm{l}$ of $\left[{ }^{32} \mathrm{P}\right] \alpha$-deoxycytidine triphosphate $(97.5 \mathrm{MBq} / \mathrm{mmol})$, and
0.5 units of Taq DNA polymerase (Toyobo, Osaka, Japan). Antibody against Taq DNA polymerase (CLONTECH Laboratories, Tokyo, Japan) was added according to the manufacturer's instruction to perform hot-start PCR to ensure proper amplification. The conditions for the thermal cycler were 10 cycles of denaturation $\left(93^{\circ} \mathrm{C}, 30 \mathrm{~s}\right)$, annealing $\left(60^{\circ} \mathrm{C}, 1 \mathrm{~min}\right)$, and extension $\left(72^{\circ} \mathrm{C}, 1 \mathrm{~min}\right)$, followed by 25 cycles of denaturation $\left(93^{\circ} \mathrm{C}, 30 \mathrm{~s}\right)$, annealing $\left(58^{\circ} \mathrm{C}, 1 \mathrm{~min}\right)$, and extension $\left(72^{\circ} \mathrm{C}, 1 \mathrm{~min}\right)$. After terminating the reaction by addition of $5 \mu \mathrm{l}$ of stop solution $(95 \%$ formamide, $5 \mathrm{mM}$ EDTA at $\mathrm{pH}$ 8.0), PCR products were resolved by $6 \%$ polyacrylamide gel containing $8 \mathrm{M}$ urea and $11 \%$ formamide followed by autoradiography. $\mathrm{LOH}$ was determined by visual inspection of the relative intensities of the bands in LAM cells in comparison to the pattern of normal cells obtained from the same tissue specimen. All analyses were repeated at least twice for confirmation of the results.

\section{Results}

Mutations of the TSC genes identified in patients with LAM

We identified six novel mutations, including three deletions, two insertions, and one nonsense mutation; three are germline mutations and the remainder are somatic mutations (Table 2). In two of six patients with TSC-LAM, germline mutations were identified. Both involved the TSC2 gene: deletion of nt993G at exon 9 in patient LKM14 and deletion of nt4891A at exon 37 in patient LTK22. The mutation identified in patient LKM14 occurred at the splice donor site of the exon 9/intron 10 boundary. RT-PCR using total RNA isolated from EBV-LCL and subsequent cloning of PCR products revealed the generation of three different mRNA transcripts: transcripts skipping exon 9, those skip- 
Table 2. Mutations of the TSC genes in patients with pulmonary lymphangioleiomyomatosis

\begin{tabular}{|c|c|c|c|c|c|}
\hline Gene & $\begin{array}{l}\text { Category of } \\
\text { mutation }\end{array}$ & Location & Nucleotide alteration & Expected protein alteration & Reference $^{\mathrm{a}}$ \\
\hline \multicolumn{6}{|c|}{ TSC-LAM } \\
\hline TSC1 & Germline & ex 9 & $\mathrm{~T} 1112 \mathrm{G}$ & Try297stop & Strizheva et al. 2001 \\
\hline TSC1 & Germline & ex 10 & C1222A & Ser334stop & Jones et al. 1999 \\
\hline$T S C 2$ & Germline & ex 9 & G898A & Gly294Arg & Strizheva et al. 2001 \\
\hline$T S C 2$ & Germline & ex 16 & $\mathrm{C} 1849 \mathrm{~T}$ & Arg611Trp & Jones et al. 1999 \\
\hline TSC2 & Germline & ex 19 & $\mathrm{~T} 2168 \mathrm{G}$ & Leu717Arg & Zhang et al. 1999 \\
\hline TSC2 & Germline & ex 23 & $\mathrm{~A} 2701 \mathrm{G}$ & Met895Val & Niida et al. 1999 \\
\hline TSC2 & Germline & ex 38 & C5042T & Pro1675Leu & Franz et al. 2001 \\
\hline TSC2 & Germline & ex 39 & C5144T & Pro1709Leu & Franz et al. 2001 \\
\hline TSC2 & Germline & ex 41 & C5401T & Arg1795Cys & Strizheva et al. 2001 \\
\hline TSC2 & Germline & ex 7 & G778T & Gln254stop & Strizheva et al. 2001 \\
\hline TSC2 & Germline & ex 19 & G2127A & Trp703stop & Niida et al. 2001 \\
\hline TSC2 & Germline & ex 29 & $\mathrm{C} 3460 \mathrm{~T}$ & Gln1148stop & Strizheva et al. 2001 \\
\hline TSC2 & Germline & ex 30 & C3773 & Ser1252stop & Strizheva et al. 2001 \\
\hline TSC2 & Germline & ex 9 & 465-bp deletion & Large deletion & Franz et al. 2001 \\
\hline$T S C 2$ & Germline & ex 9 & Del921-940 & Met301fs $\rightarrow$ aa330stop & Franz et al. 2001 \\
\hline$T S C 2$ & Germline & Many exons & Large deletion & Loss of tuberin & Jones et al. 1999 \\
\hline TSC2 & Germline & ex 18 & Del1978-79 & Gly654fs $\rightarrow$ aa655stop & Franz et al. 2001 \\
\hline TSC2 & Germline & ex 24 & Del2832-2833TA & Thr938fs $\rightarrow$ aa958stop & Beauchamp et al. 1998 \\
\hline TSC2 & Germline & ex 27 & Del3232A & Ser1072fs $\rightarrow$ aa1081stop & Franz et al. 2001 \\
\hline TSC2 & Germline & ex 37 & Del4891A & Met1625fs $\rightarrow$ aa1671stop & this study (LTK22) \\
\hline$T S C 2$ & Germline & ex 38 & Del5069-5086+16 & $\mathrm{NA}^{\mathrm{b}}$ & Franz et al. 2001 \\
\hline TSC2 & Germline & ex 40 & Del5256-5273 & 6 aa in-frame deletion & Strizheva et al. 2001 \\
\hline TSC2 & Germline & ex 9 & Del993G & Multiple splicing products & $\begin{array}{l}\text { Maruyama et al. } 2001 \\
\text { and this study (LKM14) }\end{array}$ \\
\hline$T S C 2$ & Germline & int 18 & G2116-1A & $\mathrm{NA}^{\mathrm{b}}$ & Franz et al. 2001 \\
\hline \multicolumn{6}{|c|}{ Sporadic LAM } \\
\hline TSC1 & Germline & ex 6 & C716A & Cys165stop & This study (LNK8) \\
\hline TSC2 & Somatic & ex 16 & G1850A & Arg611Gln & Carsillo et al. 2000 \\
\hline TSC2 & Somatic & ex 10 & G1114T & Glu366stop & Carsillo et al. 2000 \\
\hline TSC2 & Somatic & ex 5 & Del547-550CTTC & Leu177fs $\rightarrow$ aa180stop & Carsillo et al. 2000 \\
\hline TSC2 & Somatic & ex 18 & Del2079-2091 & Ser687fs $\rightarrow$ aa693stop & Carsillo et al. 2000 \\
\hline TSC2 & Somatic & ex 33 & Del4267C & Arg1417fs $\rightarrow$ aa1475stop & This study (LMJ7) \\
\hline TSC2 & Somatic & ex 33 & Ins4109T & Ser1364fs $\rightarrow$ aa1413stop & This study (LMJ7) \\
\hline TSC2 & Somatic & ex 40 & Ins5196-5199TGCA & His1726fs $\rightarrow$ aa1729stop & This study (LIY26) \\
\hline
\end{tabular}

Mutations of the TSC genes identified in this study and collected from literature are summarized in this table. The nucleotide number of the TSC1gene is presented in the same manner as that of Table 1. The nucleotide number of the TSC2 gene is presented by assigning the A nucleotide of the first methionine (ATG) of the TSC2 gene as nucleotide number 19

aa, amino acid; bp, base pair; Del, deletion; ex, exon; fs, frame shift; Ins, insertion; int, intron; NA, not available

${ }^{\mathrm{a}}$ The patient name was presented in the parenthesis

${ }^{\mathrm{b}}$ Protein alteration could not be estimated because the precise nucleotide or splicing alteration was not presented in the original report (Franz et al. 2001)

ping exon 9 and a part of exon 10 because of generation of a cryptic splice acceptor site in exon 10 , and those skipping exons 9 and 10 (data not shown). A deletion of nucleotide (nt) $4891 \mathrm{~A}$ at exon 37 of the TSC2 gene in patient LTK22 is expected to result in a frameshift from the position of amino acid 1671 residue and premature termination of tuberin.

On the other hand, a germline mutation, Cys165(TGC) $\rightarrow$ TG A stop on exon 6 of the TSC1 gene, was identified in only 1 (patient LNK8) of 22 patients with sporadic LAM (Table 2). The sequence of exon 6 of the TSC1 genes from her parents and elder brother was normal (data not shown), suggesting a new mutation in the patient. However, the same nonsense mutation was detected using genomic DNA isolated not only from peripheral blood leukocytes but also from normal lung tissues (panel 1 in Fig. 1), normal renal tissues (data not shown), and EBV-transformed B lymphoblastoid cell line (data not shown), suggesting a TSC1 germline mutation. Although this patient is considered genetically to be a TSC patient, the clinical phenotype was sporadic LAM because she had no clinical features characteristic of TSC. Repeated computed tomography scans of the brain failed to detect abnormalities such as cortical tubers, intracerebral calcifications, and subependymal nodules in the brain. Ophthalmologic examinations revealed no bilateral hamartomatous lesions in the optic fundi. These observations, together with the normal dermatological findings, led us to diagnose this patient as having sporadic LAM according to the clinical diagnostic criteria for TSC (Gomez 1999). Postmortem examination supported the clinical diagnosis of sporadic LAM and revealed generalized LAM lesions involving the lungs, the mediastinal lymph nodes, the kidneys, and the uterus. An examination of the brain was not allowed.

In five patients with sporadic LAM, frozen lung tissues (four patients) and lymph node (one patient) were available for mutation analysis of the TSC genes, and somatic mutations of the TSC2 gene were identified in two patients (patients LIY26 and LMJ7) (Table 2). Insertion of TGCA at 

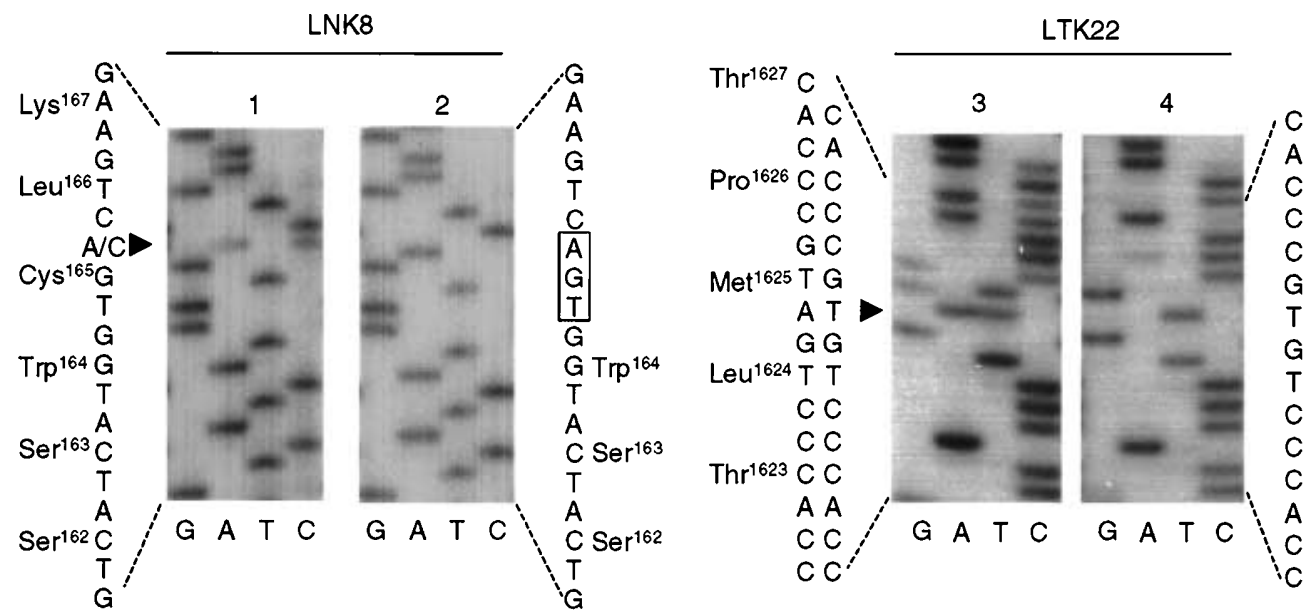

Fig. 1. Complete inactivation of the TSC genes in lymphangioleiomyomatosis (LAM) cells supports the tumor-suppressor model. Normal lung cells and LAM cells were microdissected from a formalinfixed and paraffin-embedded lung specimen and the nucleotide sequences of the TSC1 gene (patient LNK8) and the TSC2 gene (patient LTK22) were compared. In patient LNK8, a sporadic LAM with a TSC1 germline mutation (Cys165(TGㅡ) $\rightarrow$ TG $\underline{A}$ ), two bands (wild $[C]$ and mutated $[A]$ nucleotides) were observed at the same position in microdissected normal lung tissues (panel 1, indicated with an arrowhead) when sequences of the TSC1 gene coding from Ser162 to Lys167 were analyzed. However, only a mutated sequence ladder (A nucleotide) is evident in LAM cells microdissected from both the left upper lobe (panel 2) and right kidney (data not shown), showing loss of the wild-type allele. In patient LTK22, a TSC-LAM with a TSC2 germline mutation (nt4891A deletion), exon 37 of the TSC2 gene of microdissected normal cells and LAM cells was sequenced. A part of the normal and mutated nucleotide sequences ranging from Thr1623 to Thr1627 is shown on the left. Compared with the superimposed bizarre ladders after the position indicated with the arrowhead (panel 3), demonstrating the mixture of normal and mutated ladders in the microdissected normal lung cells, only the mutated sequence ladder was obtained from the microdissected LAM cells (panel 4), clearly showing loss of the wild-type allele exon 40 was identified in patient LIY26. On the other hand, two different mutations, insertion of a $\mathrm{T}$ nucleotide at $\mathrm{nt} 4109$ position and deletion of $n t 4267 \mathrm{C}$ at exon 33 of the TSC2 gene, were identified in the lymph node but not in peripheral blood leukocytes from patient LMJ7, suggesting two somatic mutations of the TSC2 gene. Cloning of PCR products of exon 33 revealed that two different mutations were on different alleles; no clone simultaneously carrying two mutations was identified. Because six lymph nodes were resected during surgery, LAM cells from the remaining five paraffin-embedded lymph nodes were microdissected to examine whether LAM cells in different lymph nodes carried the same TSC2 somatic mutations as those identified in the frozen lymph node. Both an nt4109T insertion and an $n t 4267 \mathrm{C}$ deletion were detected as superimposing sequence ladders after the site of insertion or deletion in LAM cells was microdissected from each lymph node, whereas the sequence ladder in lymphocytes microdissected from one of the paraffin-embedded lymph nodes as a control showed a normal exon 33 sequence (Fig. 2).

\section{LOH analysis of microdissected LAM cells}

In 12 of 28 patients ( 4 patients with TSC-LAM and 8 patients with sporadic LAM), paraffin-embedded tissue specimens were available for microdissecting LAM cells and subsequent $\mathrm{LOH}$ analysis. As a whole, TSC2 LOH was detected in six patients (three with TSC-LAM and three with sporadic LAM), whereas TSC1 LOH was found in only one patient (patient LNK8, sporadic LAM with a TSC1 germline mutation) (Table 3). TSC1 or TSC2 LOH at two different markers was detected in patient LNK8 (D9S149 and D9S1198) or in patient LSS6 (D16S291 and D16S525), respectively. The remaining five patients (patients LTT18, LKH2, LMJ7, LYS23, and LIY26) showed allelic loss neither at the TSC1 nor at the TSC2 locus. Representative results of $\mathrm{LOH}$ analysis of microdissected LAM cells are presented in Fig. 3 (patients LNK8, LTK22, and LJY20). There were two patients (LNK8 and LJY20) whose LAM cells were microdissected from different tissue specimens, and an identical LOH pattern was revealed in LAM cells among different specimens; both lungs, both kidneys, lymph nodes, and the uterus in patient LNK8 (Fig. 3), and angiomyolipoma and the lung in patient LJY20 (data not shown, but listed in Table 3 ).

Demonstration of two hits (inactivation of both alleles) in LAM cells

Two somatic mutations identified in LAM cells of patient LMJ7 (sporadic LAM) (Fig. 2) are very likely to indicate that LAM cells with loss of both TSC2 alleles expanded clonally and spread into adjacent lymph nodes. Complete inactivation of the TSC1 gene concordant with Knudson's tumor-suppressor model (Knudson 1971) was also observed in patient LNK8 who has a TSC1 germline mutation and whose LAM cells have TSC1 LOH at D9S149 and D9S1198 markers. When exon 6 of the TSC1 gene was examined in 


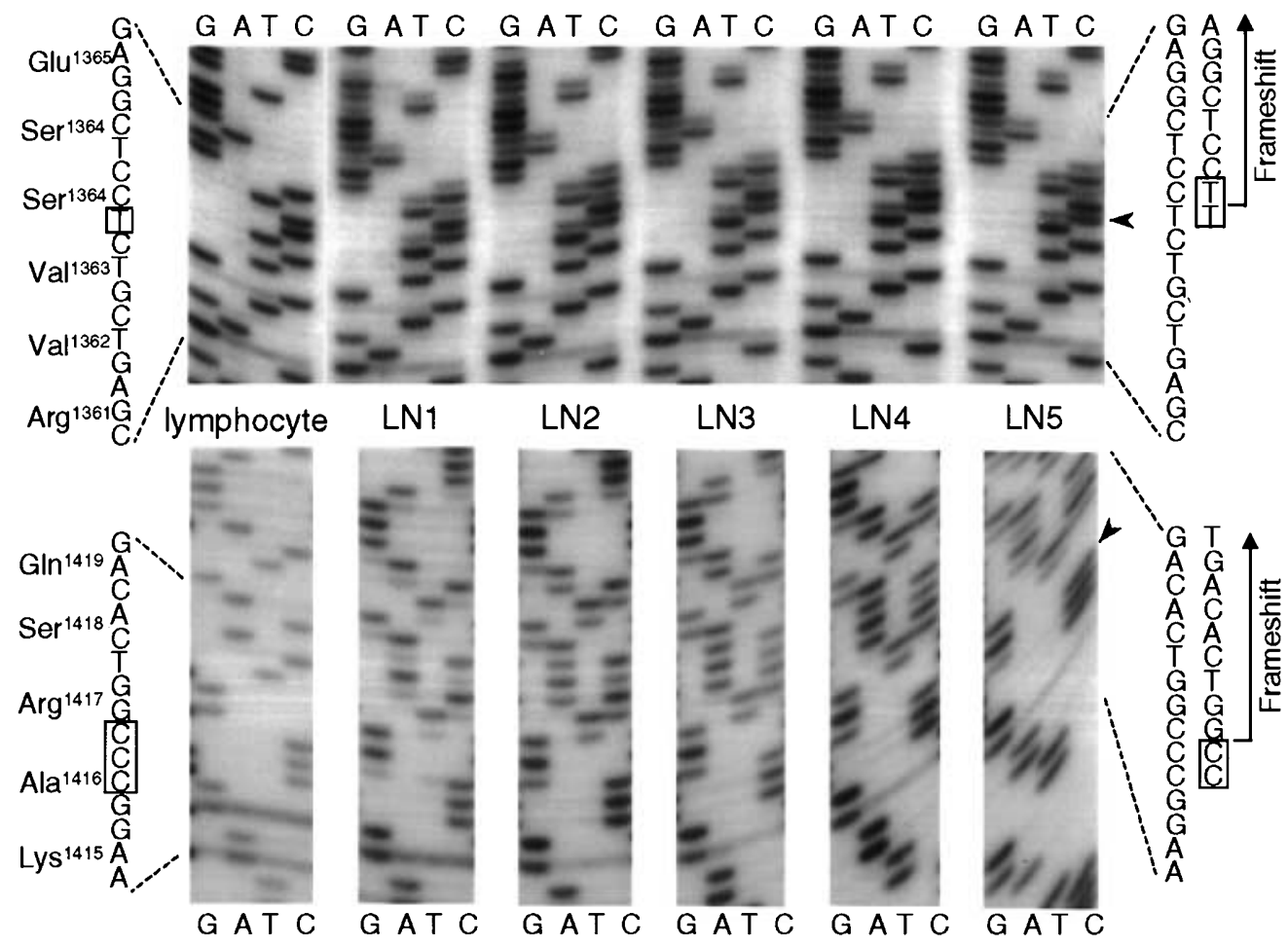

Fig. 2. Sequencing of exon 33 of the TSC2 gene in patient LMJ7 using genomic DNA isolated from paraffin-embedded tissues. LAM cells were microdissected from formalin-fixed and paraffin-embedded retroperitoneal lymph nodes; five unrelated lymph nodes were arbitrarily numbered (LN1 to LN5). Lymphocytes were microdissected as a control from one lymph node. The sequence of exon 33 of the TSC2 gene was examined using genomic DNA isolated from microdissected cells. The upper panel shows a part of the nucleotide sequence coding from Arg1361 to Glu1365 and the normal nucleotide sequence is shown on the left. Compared with the normal sequence obtained from control lymphocytes, two nucleotide sequences (shown on the right) are superimposed from the position of the $\mathrm{C}$ nucleotide of Ser1364(TCC) (indicated by the arrowhead) in LAM cells from LN1 to $\mathrm{LN}$; this is due to a $\mathrm{T}$ insertion between $\mathrm{T}$ and $\mathrm{C}$ nucleotides $(\mathrm{TCC} \rightarrow$ TTCC) in one TSC 2 allele. In the lower panel, the nucleotide sequence from Lys1415 to Gln1419 is presented in the same manner as in the upper panel. Compared with the normal sequence obtained from the lymphocytes, two nucleotide sequences (shown on the right) are superimposed from the position of the C nucleotide of Arg1417(GG) (indicated by the arrowhead) in LAM cells from LN1 to LN5 because of a C deletion (Ala1416Arg1417(GCCCGG) $\rightarrow$ GCCGG)

Table 3. LOH analysis in 12 patients with pulmonary lymphangioleiomyomatosis (LAM)

\begin{tabular}{llll}
\hline & & Allelic loss & \\
\cline { 3 - 4 } Patient & $\begin{array}{l}\text { Paraffin-embedded } \\
\text { tissue }\end{array}$ & TSC1 Markers & \\
\hline TSC-LAM & & TSC2 Markers \\
LSS6 & AML & None & \\
LKM14 & Lung & None & D16S291, D16S525 \\
LTT18 & Lung & Not amplified & D16S291 \\
LTK22 & Lung & None & Not amplified \\
Sporadic LAM & & & D16S283 \\
LKH2 & Lung & None & \\
LMJ7 & LN & None & None \\
LNK8 & Lungs, kidneys, & D9S149, D9S1198 & None \\
& lymph nodes, uterus & & None \\
LMR11 & Lung & None & D16S291 \\
LYN17 & Lung & None & D16S525 \\
LJY20 & Lung, AML & None & D16S283 \\
LYS23 & Lung & None & None \\
LIY26 & Lung & None & None \\
\hline Paffin- & & &
\end{tabular}

Paraffin-embedded tissue blocks were available in 12 patients ( 4 patients with TSC-LAM and 8 patients with sporadic LAM) for microdissection of LAM cells followed by LOH analysis (see Material and methods) AML, renal angiomyolipomas; LN, lymph nodes

${ }^{\text {a }}$ According to Smolarek et al. (1998), D9S149, D9S1198, and D9S1199 were selected as microsatellite markers at chromosome 9q34 (TSC1), and D16S283, D16S291, D16S525, and Kg8 were selected at chromosome 16p13.3 (TSC2). Microsatellite markers at which allelic loss was detected are shown in this table

${ }^{\mathrm{b}}$ No allelic loss was detected but two somatic mutations in the TSC2 gene were identified (see Table 2) 


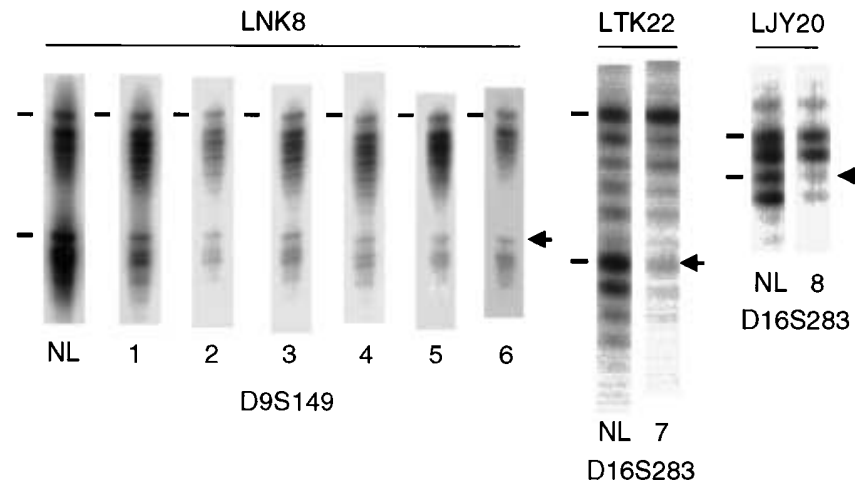

Fig. 3. Representative results of $\mathrm{LOH}$ analyses of microsatellite markers at chromosomes $9 \mathrm{q} 34$ and $16 \mathrm{p} 13$. The two alleles of each microsatellite markers are indicated with lines and the lost allele is indicated with an arrow. In patient LNK8, a sporadic LAM with a TSC1 germline mutation, the lower allele of the marker D9S149 was lost in the LAM cells microdissected from the left upper lobe of the lung (lane 1), right lower lobe of the lung (lane 2), left kidney (lane 3), right kidney (lane 4), uterus (lane 5), and mediastinal lymph node (lane 6 ), whereas two alleles of the marker D9S149 were detected in the normal lung cells (NL). In patient LTK22, a TSC-associated LAM with a TSC2 germline mutation, two alleles of the marker D16S283 were detected in the normal lung cells $(N L)$, but the lower allele was lost in the LAM cells of the lung (lane 7). In patient LJY20, a sporadic LAM with no germline mutation, the lower allele of the marker D16S283 was lost in the LAM cells microdissected from the lung (lane 8) and renal angiomyolipoma (not shown) as compared with results of the normal lung cells $(N L)$

microdissected LAM cells, only the mutated sequence ladder was evident in LAM cells of the left lung (panel 2 in Fig. 1 ), showing a loss of the wild-type allele. The results were identical in LAM cells microdissected from the right lung, kidneys, mediastinal lymph nodes, and uterus (data not shown). On the other hand, two bands (wild and mutated nucleotides) migrated at the same position in the sequence ladder of normal lung tissues (panel 1 in Fig. 1). Identical findings are obtained in patient LTK22 who has TSCassociated LAM with a TSC2 germline mutation (nt4891A deletion in exon 37) and whose LAM cells revealed $\mathrm{LOH}$ at D16S283. When exon 37 of the TSC2 gene was analyzed, only the nt4891A-deleted sequence was observed because of loss of the wild-type sequence (panel 4 in Fig. 1) in LAM cells, whereas the sequence ladder superimposing the wild type and the deleted alleles in normal cells was observed (panel 3 in Fig. 1).

\section{Discussion}

We performed mutation analysis of the TSC1 and TSC2 genes in 28 Japanese patients with pulmonary LAM, consisting of 6 patients with TSC-LAM and 22 patients with sporadic LAM, and we report six novel mutations. Germline mutation was detected in two (33\%) of six patients with TSC-LAM, both being deletions on the TSC2 gene. One of two germline mutations detected (patient LKM14) was the splice site mutation first reported to be involved in LAM, which resulted in multiple splicing products of TSC2 mRNA transcripts. Her clinical phenotype is characterized by multifocal micronodular pneumocyte hyperplasia and LAM of the lungs and has already been reported, with special emphasis on immunohistochemical findings (Maruyama et al. 2001). On the other hand, germline mutation was detected in one $(4.5 \%)$ of 22 patients with sporadic LAM, whereas the majority of patients with sporadic LAM had neither of TSC1 nor TSC2 germline mutations. Our detection rate of germline mutations in patients with TSC-LAM appears to be almost identical to that of several studies on mutation analysis in patients with TSC (Au et al. 1998; Jones et al. 1997; Kwiatkowska et al. 1998; Van Bakel et al. 1997; Wilson et al. 1996; Yamashita et al. 2000) but lower than that of other studies (Cheadle et al. 2000; Dabora et al. 2001; Jones et al. 1999; Niida et al. 1999; Strizheva et al. 2001). The detection rate varies widely from $37 \%$ to $83 \%$, depending on the screening method used. A recent study (Dabora et al. 2001) using a variety of screening methods, including heterpoduplex analysis, denaturing high-performance liquid chromatography, and quantitative PCR reported the highest detection rate $(83 \%)$. The low detection rate in our study is likely due to the fact that the size of the TSC-LAM group is small or the fact that we only used SSCP and ddF among a variety of screening methods available. Thus we might have failed to detect TSC germline mutations in the remaining four TSC-LAM patients.

Pathogenesis and development of sporadic LAM has been established by a series of studies by Henske's group (Astrinidis et al. 2000; Carsillo et al. 2000; Smolarek et al. 1998). First, sporadic LAM is a TSC2 disease; TSC-LAM is caused much less frequently by TSC1 mutations than by TSC2 mutations (Strizheva et al. 2001). Second, patients with sporadic LAM have no TSC2 germline mutation (Astrinidis et al. 2000), whereas patients with TSC-LAM have a germline mutation (Strizheva et al. 2001). Lastly, sporadic LAM is caused by two successive somatic mutations of the TSC2 gene, and LAM cells with complete inactivation of TSC2 function can spread to from one lesion to another (Carsillo et al. 2000). Our study on Japanese LAM patients clearly support their observations: two of six patients with TSC-LAM had TSC2 germline mutations; 21 of 22 patients with sporadic LAM had neither a TSC1 nor a TSC2 germline mutation; LAM cells showed LOH in three of four patients with TSC-LAM who were examined and in four of eight patients with sporadic LAM who were tested; complete loss of TSC1 or TSC2 function was demonstrated in LAM cells of one patient with sporadic LAM and in one patient with TSC-LAM, respectively; and finally, we detected that LAM cells microdissected from several tissues had identical LOH or two identical somatic mutations, suggesting LAM cells can spread from one lesion to another. In addition to confirming the established pathogenesis of LAM, our study suggests the importance of analyzing both TSC1 and TSC2 genes, not only in patients with TSC-LAM, but also in patients with sporadic LAM. Our identification of a phenotypically sporadic LAM that was genetically a forme fruste of TSC because of a TSC1 germline mutation 
underlines the importance of analyzing mutations of not only the TSC2 but also of the TSC1 gene. However, further studies are needed to determine the percentage of sporadic LAM patients who have a forme fruste of TSC-carrying TSC germline mutations. In addition, the fraction of patients with sporadic LAM from a TSC1 disease remains unsolved; also unknown is whether there is a patient who has no germline mutation but develops sporadic LAM with two successive somatic mutations of the TSC1 gene rather than a forme fruste of TSC, as revealed in patient LNK8.

There seems to be a variety of mutations causing LAM when the mutations reported in the literature are considered (Beauchamp et al. 1998; Carsillo et al. 2000; Franz et al. 2001; Jones et al. 1999; Maruyama et al. 2001, Niida et al. 1999, 2001; Strizheva et al. 2001; Zhang et al. 1999) and reviewed together with the mutations identified by our study (Table 2). There are 32 different mutations reported to cause LAM, 24 for TSC-LAM and 8 for sporadic LAM. No specific mutation has been reported to be frequently detected in patients with LAM except for Del5256-5273 on exon 40 of the TSC2 gene found in two unrelated patients with TSC-LAM (Strizheva et al. 2001). As for TSC-LAM, two TSC1 and four TSC2 nonsense mutations, seven TSC2 missense mutations, nine TSC2 deletions, and two splice site mutations were reported. On the other hand, deletion and insertion are the most frequent type of mutation (five of eight mutations reported) in sporadic LAM followed by one each for the TSC1 and TSC2 nonsense mutations and one TSC 2 missense mutation. Recently, Strizheva et al. (2001) raised the possibility that mutations in exons 40 and 41 of the TSC2 gene are associated with a higher incidence of LAM than are mutations elsewhere in the TSC2 gene. All five TSC2 mutations newly identified in our study are expected to lose the carboxy terminus of tuberin encoded by exons 40 and 41 ; in total, 22 (76\%) of 29 TSC2 mutations causing LAM are likely to fit into this category.

Why are TSC2 mutations much more prevalent in LAM than are TSC1 mutations? Since hamartin and tuberin associate together (Nellist et al. 1999; Plank et al. 1998; Van Slegtenhorst et al. 1998) and regulate the cell cycle (Miloloza et al. 2000; Soucek et al. 1997), it can be postulated that the development of LAM is due to the mutation of either the $T S C 1$ or the $T S C 2$ gene. It remains unclear why there is a higher predilection for a TSC2 abnormality observed in LAM than in TSC in this and other studies (Carsillo et al. 2000; Smolarek et al. 1998), but it may be explained as follows. First, we and others might have missed enrolling sporadic LAM patients with TSC1 mutations. It has recently been demonstrated that TSC patients with TSC1 mutations are less severely affected in multiple clinical measures related to the brain, kidney, skin, and retina (Dabora et al. 2001; Jones et al. 1999). Because LAM is known to have a broad clinical spectrum, only the group of patients who manifest symptoms severe enough to seek medical attention because of TSC2 abnormalities might enroll for genetic analysis. Second, the TSC2 gene may be more susceptible to acquiring mutations because the TSC2 gene is larger than the TSC1 gene and spreads over about $44 \mathrm{~kb}$ of genomic DNA (The European Chromosome 16 Tuberous Sclerosis Con- sortium 1993). However, about half of the familial TSC cases showed linkage to the TSC1 gene (9q34) and the remainder to the TSC2 gene (16p13.3) (Povey et al. 1994), TSC2 mutations account for about $70 \%$ of TSC cases (Cheadle et al. 2000) and are five times more common in sporadic TSC patients than are TSC1 mutations. Dabora et al. (2001) reported that both germline and somatic mutations were less common in TSC1 than in TSC2 in a large cohort of TSC patients. The role of $T S C 1$ in the development of sporadic LAM, for which two successive somatic mutations are required, may decrease if $T S C 1$ is less prone to mutation than is TSC2. Lastly, the skewed mutational frequency may suggest that the hamartin and tuberin have distinct functions and tuberin commits more to the differentiation and proliferation of smooth muscle cells. Future studies are needed to compare the clinical severity of TSC-LAM associated with a TSC1 germline mutation and TSC-LAM associated with a TSC2 germline mutation, and to analyze mutations in sporadic LAM with a mild phenotype.

Acknowledgments This study is supported in part by Grant-in-Aid for Scientific Research No. 11770315 from the Japan Society for the Promotion of Scientific Research. The authors thank the following doctors for their cooperation: Dr. T. Ishihara, Kanto Medical Center NTTEC; Dr. N. Kusuhara and Dr. I. Higa, Hiratsuka City Hospital; Dr. N. Kohno and Dr. K. Konodo, Second Department of Internal Medicine, Ehime University; Dr. J. Kono, Fukuoka-Higashi National Hospital; Dr. T. Sawai, First Department of Pathology, Iwate Medical University; Dr. Y. Sandoh, Second Department of Internal Medicine, Gunma University; Dr. M. Fujino, Matsudo City Medical Center; Dr. R. Matsuoka, Showa General Hospital; and Dr. K. Kudo, International Medical Center of Japan.

\section{References}

Astrinidis A, Khare L, Carsillo T, Smolarek T, Au K, Northrup H, Henske E (2000) Mutational analysis of the tuberous sclerosis gene TSC2 in patients with pulmonary lymphangioleiomyomatosis. J Med Genet 37:55-57

Au KS, Rodriguez JA, Finch JL, Volcik KA, Roach ES, Delgado MR, Rodriguez E Jr, Northrup H (1998) Germ-line mutational analysis of the TSC2 gene in 90 tuberous-sclerosis patients. Am J Hum Genet 62:286-294

Beauchamp RL, Banwell A, McNamara P, Jacobsen M, Higgins E, Northrup H, Short P, Sims K, Ozelius L, Ramesh V (1998) Exon scanning of the entire TSC2 gene for germline mutations in 40 unrelated patients with tuberous sclerosis. Hum Mutat 12:408-416

Carsillo T, Astrinidis A, Henske E (2000) Mutations in the tuberous sclerosis complex gene TSC2 are a cause of sporadic pulmonary lymphangioleiomyomatosis. Proc Natl Acad Sci USA 97:60856090

Castro M, Shepherd C, Gomez M, Lie J, Ryu J (1995) Pulmonary tuberous sclerosis. Chest 107:189-195

Cheadle JP, Reeve MP, Sampson JR, Kwiatkowski DJ (2000) Molecular genetic advances in tuberous sclerosis. Hum Genet 107:97-114

Chu S, Horiba K, Usuki J, Avila N, Chen C, Travis W, Ferrans V, Moss J (1999) Comprehensive evaluation of 35 patients with lymphangioleiomyomatosis. Chest 115:1041-1052

Corrin B, Liebow AA, Friedman PJ (1975) Pulmonary lymphangiomyomatosis. A review. Am J Pathol 79:348-382

Dabora S, Jozwiak S, Franz D, Roberts P, Nieto A, Chung J, Choy Y, Reeve M, Thiele E, Egelhoff J, Kasprzyk-Obara J, DomanskaPakiela D, Kwiatkowski D (2001) Mutational analysis in a cohort of 224 tuberous sclerosis patients indicates increased severity of TSC2, compared with TSC1, disease in multiple organs. Am J Hum Genet 68:64-80 
The European Chromosome 16 Tuberous Sclerosis Consortium (1993) Identification and characterization of the tuberous sclerosis gene on chromosome 16. Cell 75:1305-1315

Franz DN, Brody A, Meyer C, Leonard J, Chuck G, Dabora S, Sethuraman G, Colby TV, Kwiatkowski DJ, McCormack FX (2001) Mutational and radiographic analysis of pulmonary disease consistent with lymphangioleiomyomatosis and micronodular pneumocyte hyperplasia in women with tuberous sclerosis. Am J Respir Crit Care Med 164:661-668

Fujii H, Marsh C, Cairns P, Sidransky D, Gabrielson E (1996) Genetic divergence in the clonal evolution of breast cancer. Cancer Res 56:1493-1497

Gomez MR (1999) Definition and criteria for diagnosis. In: Gomez MR (ed) Tuberous sclerosis complex, 3rd edn. Oxford University Press, New York, pp 10-23

Henske EP, Scheithauer BW, Short MP, Wollmann R, Nahmias J, Hornigold N, van Slegtenhorst M, Welsh CT, Kwiatkowski DJ (1996) Allelic loss is frequent in tuberous sclerosis kidney lesions but rare in brain lesions. Am J Hum Genet 59:400-406

Johnson SR, Tattersfield AE (1999) Decline in lung function in lymphangioleiomyomatosis: relation to menopause and progesterone treatment. Am J Respir Crit Care Med 160:628-633

Jones AC, Daniells CE, Snell RG, Tachataki M, Idziaszczyk SA, Krawczak M, Sampson JR, Cheadle JP (1997) Molecular genetic and phenotypic analysis reveals differences between TSC1 and TSC2 associated familial and sporadic tuberous sclerosis. Hum Mol Genet 6:2155-2161

Jones AC, Shyamsundar MM, Thomas MW, Maynard J, Idziaszczyk S, Tomkins S, Sampson JR, Cheadle JP (1999) Comprehensive mutation analysis of TSC1 and TSC2-and phenotypic correlations in 150 families with tuberous sclerosis. Am J Hum Genet 64:13051315

Knudson AG Jr (1971) Mutation and cancer: statistical study of retinoblastoma. Proc Natl Acad Sci USA 68:820-823

Kwiatkowska J, Jozwiak S, Hall F, Henske EP, Haines JL, McNamara P, Braiser J, Wigowska-Sowinska J, Kasprzyk-Obara J, Short MP, Kwiatkowski DJ (1998) Comprehensive mutational analysis of the TSC1 gene: observations on frequency of mutation, associated features, and nonpenetrance. Ann Hum Genet 62:277-285

Maruyama H, Seyama K, Sobajima J, Kitamura K, Sobajima T, Fukuda T, Hamada K, Tsutsumi M, Hino O, Konishi Y (2001) Multifocal micronodular pneumocyte hyperplasia and lymphangioleiomyomatosis in tuberous sclerosis with a TSC2 gene. Mod Pathol 14:609-614

Miloloza A, Rosner M, Nellist M, Halley D, Bernaschek G, Hengstschlager M (2000) The TSC1 gene product, hamartin, negatively regulates cell proliferation. Hum Mol Genet 9:1721-1727

Nellist M, van Slegtenhorst MA, Goedbloed M, van den Ouweland AM, Halley DJ, van der Sluijs P (1999) Characterization of the cytosolic tuberin-hamartin complex. Tuberin is a cytosolic chaperone for hamartin. J Biol Chem 274:35647-35652

Niida Y, Lawrence-Smith N, Banwell A, Hammer E, Lewis J, Beauchamp RL, Sims K, Ramesh V, Ozelius L (1999) Analysis of both TSC1 and TSC2 for germline mutations in 126 unrelated patients with tuberous sclerosis. Hum Mutat 14:412-422

Niida Y, Stemmer-Rachamimov AO, Logrip M, Tapon D, Perez R, Kwiatkowski DJ, Sims K, MacCollin M, Louis DN, Ramesh V (2001) Survey of somatic mutations in tuberous sclerosis complex (TSC) hamartomas suggests different genetic mechanisms for pathogenesis of TSC lesions. Am J Hum Genet 69:493-503

Plank TL, Yeung RS, Henske EP (1998) Hamartin, the product of the tuberous sclerosis 1 (TSC1) gene, interacts with tuberin and appears to be localized to cytoplasmic vesicles. Cancer Res 58:47664770

Povey S, Burley MW, Attwood J, Benham F, Hunt D, Jeremiah SJ, Franklin D, Gillett G, Malas S, Robson EB, Tippett P, Edwards JH, Kwiatkowski DJ, Super M, Mueller R, Fryer A, Clarke A, Webb D,
Osborne J (1994) Two loci for tuberous sclerosis: one on 9q34 and one on 16p13. Ann Hum Genet 58:107-127

Sarkar G, Yoon HS, Sommer SS (1992) Dideoxy fingerprinting (ddE): a rapid and efficient screen for the presence of mutations. Genomics 13:441-443

Sepp T, Yates JR, Green AJ (1996) Loss of heterozygosity in tuberous sclerosis hamartomas. J Med Genet 33:962-964

Seyama K, Kira S, Takahashi H, Ohnishi M, Kodama Y, Dambara T, Kobayashi J, Kitamura S, Fukuchi Y (2001) Longitudinal followup study of eleven patients with pulmonary lymphangioleiomyomatosis (LAM): diverse clinical courses of LAM allow some patients to be treated without anti-hormone therapy. Respirology 6:331-339

Short MP, Richardson EP Jr, Haines JL, Kwiatkowski DJ (1995) Clinical, neuropathological and genetic aspects of the tuberous sclerosis complex. Brain Pathol 5:173-179

Silverstein EF, Ellis K, Wolff M, Jaretzki A 3rd (1974) Pulmonary lymphangiomyomatosis. Am J Roentgenol Radium Ther Nucl Med 120:832-850

Smolarek T, Wessner L, McCormack F, Mylet J, Menon A, Henske E (1998) Evidence that lymphangiomyomatosis is caused by TSC2 mutations: chromosome $16 \mathrm{p} 13$ loss of heterozygosity in angiomyolipomas and lymph nodes from women with lymphangiomyomatosis. Am J Hum Genet 62:810-815

Soucek T, Pusch O, Wienecke R, DeClue JE, Hengstschlager M (1997) Role of the tuberous sclerosis gene- 2 product in cell cycle control. Loss of the tuberous sclerosis gene- 2 induces quiescent cells to enter S phase. J Biol Chem 272:29301-29308

Strizheva GD, Carsillo T, Kruger WD, Sullivan EJ, Ryu JH, Henske EP (2001) The spectrum of mutations in TSC1 and TSC2 in women with tuberous sclerosis and lymphangiomyomatosis. Am J Respir Crit Care Med 163:253-258

Urban T, Lazor R, Lacronique J, Murris M, Labrune S, Valeyre D, Cordier J (1999) Pulmonary lymphangioleiomyomatosis. A study of 69 patients. Groupe d'Etudes et de Recherche sur les Maladies "Orphelines" Pulmonaires (GERM"O"P). Medicine (Baltimore) 78:321-337

Van Bakel I, Sepp T, Ward S, Yates JR, Green AJ (1997) Mutations in the TSC2 gene: analysis of the complete coding sequence using the protein truncation test (PTT). Hum Mol Genet 6:14091414

Van Slegtenhorst M, de Hoogt R, Hermans C, Nellist M, Janssen B, Verhoef S, Lindhout D, van den Ouweland A, Halley D, Young J, Burley M, Jeremiah S, Woodward K, Nahmias J, Fox M, Ekong R, Osborne J, Wolfe J, Povey S, Snell RG, Cheadle JP, Jones AC, Tachataki M, Ravine D, Sampson JR, Reeve MP, Richardson P, Wilmer F, Munro C, Hawkins TL, Sepp T, Ali JBM, Ward S, Green AJ, Yates JRW, Kwiatkowska J, Henske EP, Short MP, Haines JH, Jozwiak S, Kwiatkowski DJ (1997) Identification of the tuberous sclerosis gene TSC1 on chromosome 9q34. Science 277:805-808

Van Slegtenhorst M, Nellist M, Nagelkerken B, Cheadle J, Snell R, Ouweland Avd, Reuser A, Sampson J, Halley D, Sluijs Pvd (1998) Interaction between hamartin and tuberin, the TSC1 and TSC2 gene products. Hum Mol Genet 7:1053-1057

Wilson PJ, Ramesh V, Kristiansen A, Bove C, Jozwiak S, Kwiatkowski DJ, Short MP, Haines JL (1996) Novel mutations detected in the TSC2 gene from both sporadic and familial TSC patients. Hum Mol Genet 5:249-256

Yamashita Y, Ono J, Okada S, Wataya-Kaneda M, Yoshikawa K, Nishizawa M, Hirayama Y, Kobayashi E, Seyama K, Hino O (2000) Analysis of all exons of TSC1 and TSC2 genes for germline mutations in Japanese patients with tuberous sclerosis: report of 10 mutations. Am J Med Genet 90:123-126

Zhang H, Yamamoto T, Nanba E, Kitamura Y, Terada T, Akaboshi S, Yuasa I, Ohtani K, Nakamoto S, Takeshita K, Ohno K (1999) Novel TSC2 mutation in a patient with pulmonary tuberous sclerosis: lack of loss of heterozygosity in a lung cyst. Am J Med Genet 82:368370 